\title{
Implementasi Pola Tata Ruang Desa Pesisir Di Kabupaten Bangka Selatan (Studi Kasus Desa Tukak)
}

\author{
Urban Planning Implementation in South Bangka Regency (Study Case at Tukak Coastal Village)
}

\author{
Wahyu Adi ${ }^{1}$, Dwi Rizka Zulkia ${ }^{2}$, Kurniawan ${ }^{3}$, dan Aditya Pamungkas ${ }^{4}$ \\ ${ }^{1,3,4}$ Program Studi Manajemen Sumberdaya Perairan, Universitas Bangka Belitung \\ ${ }^{2}$ Pusat Kajian Sumberdaya Perairan dan Pulau Kecil (PKSP2K), Universitas Bangka Belitung \\ Email korespondensi: wahyuadi@ubb.ac.id; emailwahyuadi@gmail.com
}

Diterima maret 2019; disetujui April 2019; tersedia secara online April 2019

\begin{abstract}
This study aims to find out how the suitability of urban planning implementation in the South Bangka Regency (Study Case at Tukak Coastal Village)based on Government Spatial Plan (RTRW). The research method used is descriptive qualitative method. Data analysis will be carried out by using the survey results in the form of a questionnaire to find out community perceptions regarding regional spatial patterns in Tukak Village, analyzing the suitability of spatial use with the South Bangka Regency RTRW and the drivers of land change. The survey results will also be used to determine the level of land suitability in Tukak Village and analyzed using GIS (Geographic Information System). The research instruments that will be used in the analysis are observation, ground check, interviews, documentation, and data processing using the GIS application. From the results of research that has been done, it is known that in the implementation of spatial patterns in Tukak Village there are about 1,904.33 ha of land use in Tukak Village which is not in accordance with the District Spatial Plan. South Bangka. Good socialization and understanding of spatial planning has not been thoroughly obtained by the community and they support the evaluation of the layout of the Tukak Village in accordance with the District Spatial Plan. South Bangka.
\end{abstract}

Keywords : GIS, implementation, spatial pattern, urban planning

\section{PENDAHULUAN}

Pemanfaatan ruang yang berkualitas dapat tercapai dengan adanya penataan ruang wilayah yang baik (Subagyo, 2017 $7^{\text {; }}$ Wirosoedarmo dkk, 2014 ${ }^{\mathrm{ii}}$ ). Oleh karena itu sangat diperlukan pengendalian melalui kegiatan pemantauan dan evaluasi terhadap pemanfaatan ruang yang telah ada. Sebagaimana yang dikemukakan dalam Undang-Undang Penataan Ruang Nomor 26 Tahun 2007 bahwa pengawasan terhadap pemanfaatan ruang diselenggarakan dalam bentuk pelaporan, pemantauan dan evaluasi oleh pemerintah daerah sesuai dengan kewenangannya. Melalui kegiatan pemantauan dan evaluasi, kesesuaian pemanfataan ruang sesuai dengan fungsi yang telah ditetapkan dapat diwujudkan. Dengan demikian pemanfaatan ruang termasuk didalamnya struktur ruang dan pola ruang selayaknya sesuai dengan rencana tata ruang. Pemanfaatan ruang di Kabupaten Bangka Selatan harus mengacu kepada Peraturan Daerah tentang Rencana Tata Ruang Wilayah (RTRW) Kabupaten Bangka Selatan Tahun 2014-2034 sehingga tidak terjadi penyimpangan dalam pemanfaatan ruang (BIG, 2018) ${ }^{\mathrm{iii}}$.

Berbagai kendala Pemerintah Daerah dalam mewujudkan pembangunan wilayah kabupaten sesuai dengan rencana tata ruang wilayah Kabupaten diantaranya disebabkan oleh faktor-faktor seperti kondisi topografi wilayah (Rully, 2016 ${ }^{\text {iv }}$; Hidayati dan Toyibullah, 2011 ${ }^{\mathrm{v}}$ ), keterbatasan sumber daya baik sumber daya alam maupun sumber daya social (Anoraga, 2018 ${ }^{\mathrm{vi}}$; Napitupulu dkk, 2016 ${ }^{\mathrm{vii}}$ ), dan pola pikir masyarakat di bagian wilayah tertentu yang belum bisa

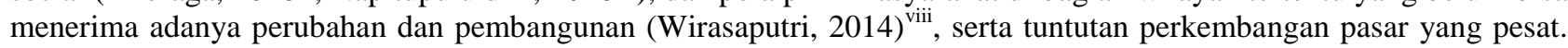
Oleh sebab itu sangat dirasakan pentingnya suatu kegiatan evaluasi terhadap produk rencana tata ruang yang telah ada seperti Dokumen RTRW untuk melihat apakah produk tersebut berjalan sesuai dengan pemanfaatannya atau telah terjadi penyimpangan. Kegiatan evaluasi ini lebih ditekankan pada kegiatan pemantauan penyimpangan terhadap pemanfaatan ruang yang merupakan bagian dari kegiatan pengawasan pemanfaatan ruang dalam pengendalian pemanfaatan ruang sesuai dengan amanat yang ditegaskan dalam Undang Undang Penataan Ruang No. 26 tahun 2007.

Desa Tukak merupakan daerah pesisir dan sebagian besar $(81,84 \%)$ kawasan desa tersebut telah ditetapkan sebagai kawasan strategis provinsi dalam Rencana Tata Ruang Wilayah Kabupaten Bangka Tahun 2014-2034 yaitu Kawasan Minapolitan Tukak Sadai dan Kawasan Industri Terpadu Pelabuhan Tukak Sadai sebagai wujud dukungan terhadap kehidupan ekonomi masyarakat di Kabupaten Bangka Selatan. Pengembangan kawasan strategis industri sebagai kawasan strategis sosial ekonomi melalui penataan dan pemanfaatan ruang serta pembangunan jaringan infrastruktur yang mendorong perkembangan kawasan. Oleh karena itu, Desa Tukak dinyatakan sebagai satu daerah yang sedang berada dalam proses perubahan lahan. Proses ini terjadi akibat adanya faktor-faktor yang mendorong perubahan lahan itu terjadi seperti lahan pertanian yang dahulu mendominasi daerah tersebut kini telah banyak 
dikonversi menjadi kawasan industri beserta jaringannya, fasilitas umum, tempat wisata dan lain sebagainya yang memberikan pengaruh kepada masyarakat.

Faktor pendorong yang lain ialah karena tuntutan ekonomi yang memaksa masyarakat sekitar untuk menjual persawahan, perkebunan, ladang kepada pemilik proyek industri yang akan merubah lahan tersebut baik dalam jangka waktu cepat ataupun lambat. Maka secara cepat atau lambat pula daerah sekitar akan menemui permasalahan seperti pencemaran udara akibat dari proses industri, limbah yang semakin hari semakin menumpuk, kurangnya ruang terbuka hijau didaerah tersebut, warga sekitar tidak bisa merasakan hasil panen seperti biasanya, dan akan menjadi ketidakseimbangan.

Pemerintah daerah sebagai salah satu peran yang cukup besar untuk menjaga kesetabilan antara ruang yang dapat diolah untuk mendukung suatu daerahnya dengan ruang yang seharusnya tetap utuh dijaga untuk keseimbangan penggunaan lahan. Dalam era teknologi sekarang seharusnya pemerintah membuat suatu informasi mengenai pemanfaatan ruang yang ideal dan daerah-daerah mana saja yang potensial untuk mendukung daerah tersebut baik dari segi penempatan kawasan industri, pemanfaatan ruang terbuka hijau dan lain sebagainya yang dapat diakses oleh semua masyarakat, agar masyarakat mengetahui pemanfaatan daerahnya sehingga sesuai dengan apa yang diharapkan.

Masalah pembangunan juga erat kaitannya dengan kebijakan pemerintah daerah. Kerjasama pembangunan tersebut tentu saja sebelumnya telah menjadi wacana yang didiskusikan dengan seksama antara investor dengan perusahaan terkait dengan para petinggi pemerintah, termasuk perangkat desa yang semestinya selalu melakukan pengkontrolan atas kebijakan yang telah disepakati bersama. Kajian mengenai kesesuaian lahan sangat penting dilakukan agar menjadi acuan bagi kegiatan pembangunan disuatu daerah. Konversi lahan dari satu fungsi ke fungsi yang lainnya harus diperhitungkan dengan seksama.

Penelitian ini bertujuan mengevaluasi kesesuaian implementasi pola tata ruang kawasan Desa Tukak dengan RTRW Kabupaten Bangka Selatan. Tujuan selanjutnya dari penelitian ini adalah membuat rekomendasi berdasarkan hasil evaluasi terhadap pola tata ruang di kecamatan pesisir di Kabupaten Bangka Selatan.

\section{METODE PENELITIAN}

Metode yang digunakan dalam penelitian ini, mengacu pada Batudoka $(2005)^{\mathrm{ix}}$ menggunakan metode survey dan pemetaan dengan langkah-langkah kegiatan sebagai berikut :

a. Setelah persiapan awal prasurvey, selanjutnya dilakukan pengumpulan bahan-bahan pemantauan dan evaluasi berupa produk rencana tata ruang yaitu dokumen RTRW Kabupaten Bangka Selatan serta data-data sekunder lainnya seperti peta perubahan penggunaan lahan terakhir, peta batas administrasi desa dan kecamatan, data rencana kegiatan/proyek sektoral dan daerah per tahun (APBD/APBN Kabupaten);

b. Melakukan survei lapangan di lokasi pemantauan dan evaluasi melalui lembar tabulasi pendataan primer untuk melihat kondisi eksisting terhadap pemanfaatan dan struktur ruang yang ada saat ini (tahun pemantauan);

c. Pemetaan di lokasi pemantauan menggunakan peta-peta dasar rencana yang telah ada dengan cara tumpangsusun (overlay) untuk memantau kondisi eksisting yaitu keberadaan pemanfaatan ruang dan letak prasarana dan sarana sebagai wujud dari struktur ruang;

d. Selanjutnya, hasil survei lapangan ini kemudian dihimpun, diolah, dan dianalisis untuk memantau besarnya penyimpangan yang terjadi antara kondisi eksisting dan rencana yang telah disusun pada produk RTRW di lokasi pemantauan;

e. Pada bagian akhir adalah penyusunan rekomendasi berdasarkan hasil pemantauan dan evaluasi yang dilaksanakan di Kabupaten Bangka Selatan.

\section{Sumber Data}

Data Spasial (Primer). Sumber data primer yang dibutuhkan pada penelitian ini adalah bersumber dari aplikasi berbasis Sistem Informasi Geografi, dalam aplikasi tersebut akan terlihat bagaimana perubahan lahan yang terjadi di Desa Tukak Sadai yang mana dari hasil persebaran tersebut akan dibuktikan melalui observasi, wawancara dan dokumentasi.

Data Atribut (Sekunder). Sumber data sekunder diperoleh dari sumber lain seperti Badan Pusat Statistik, Badan PPPD Kabupaten Bangka Selatan, Kecamatan Tukak Sadai, buku, jurnal ataupun artikel.

\section{Pengolahan Data Spasial}

Cropping Citra (pemotongan citra) pada koordinat tertentu pada area citra dengan menggunakan polygon batas administrasi. Ground Check (Pemeriksaan Lapangan) untuk melihat kembali hasil interpretasi objek atau penggunaan lahan, pengamatan penggunaan lahan berdasarkan pta penggunaan lahan yang sudah ada secara fisik. Analisis Perubahan Lahan dengan membandingkan persebaran dan perubahan kawasan pada tahun 2014 dan Tahun 2018.

\section{Pengolahan Data Atribut}

Pengolahan data atribut dimaksudkan agar data yang sudah terkumpul memberikan gambaran mengenai perubahan penutupan lahan yang terjadi di lapangan dengan RTRW Kabupaten Bangka Selatan. Pengolahan data atribut ini melalui survey lapangan berdasarkan titik groundcheck yang telah dibuat, wawancara, observasi terhadap kondisi di lapangan dan dokumentasi. 


\section{Analisis Data}

Analisis Data dilakukan berdasarkan hasil tampilan dan overlay antara citra yang telah diklasifikasikan menjadi bentuk peta penutupan lahan dengan peta digital.

\section{HASIL DAN PEMBAHASAN}

Analisis kesesuaian penggunaan lahan eksisting terhadap rencana pola ruang RTRW Kabupaten Bangka Selatan dilakukan dengan melakukan penentuan titik lokasi (groundcheck) yang akan dijadikan sampel dalam interpretasi citra. Hasil analisis ini menghasilkan dua jenis kesesuaian, yaitu penggunaan lahan yang sudah sesuai maupun tidak sesuai dengan rencana pola ruang, serta rencana pola ruang yang belum terlaksana sehingga penggunaan lahan masih dapat berubah sesuai dengan rencana pola ruang.

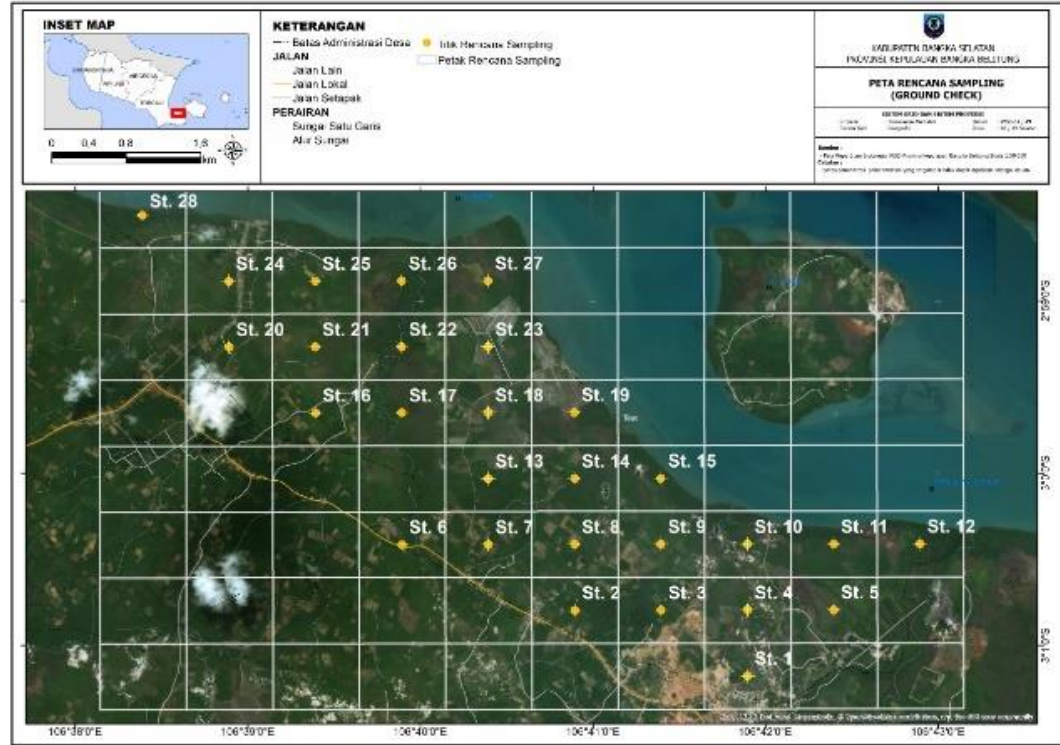

Gambar 1. Titik Pengamatan data lapangan (groundcheck)

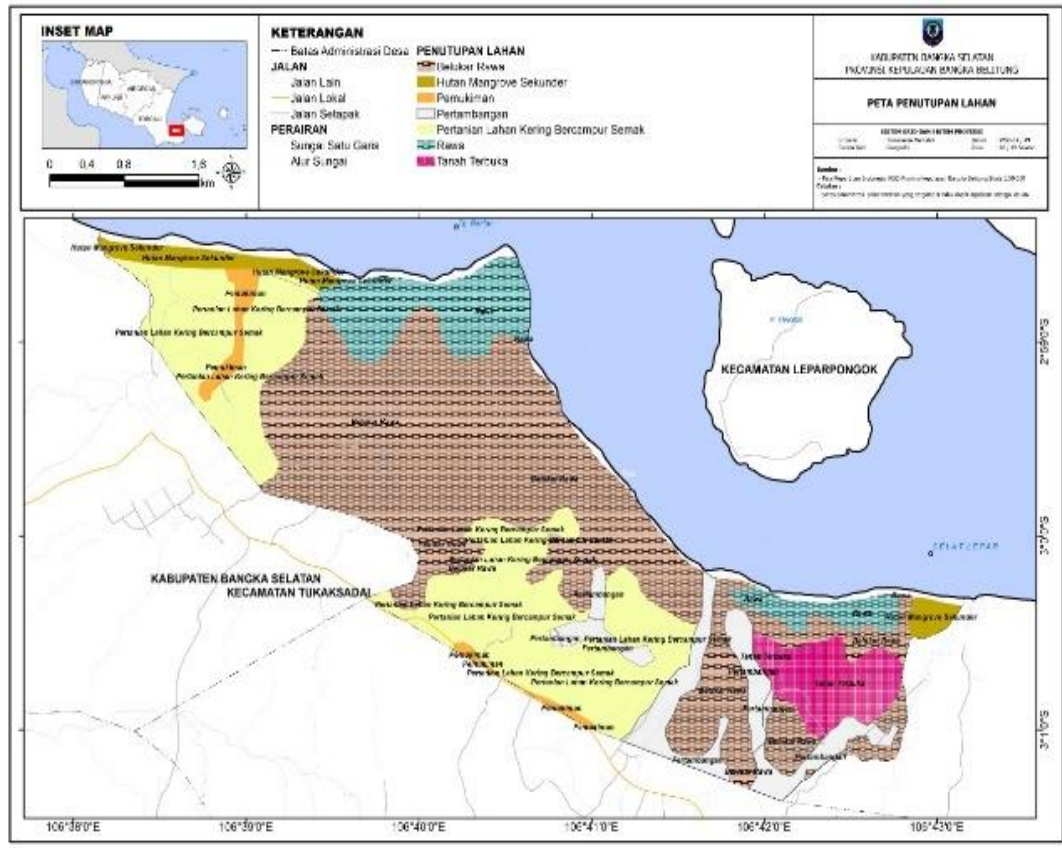

Gambar 2. Peta Penutupan Lahan (tahun 2017) 


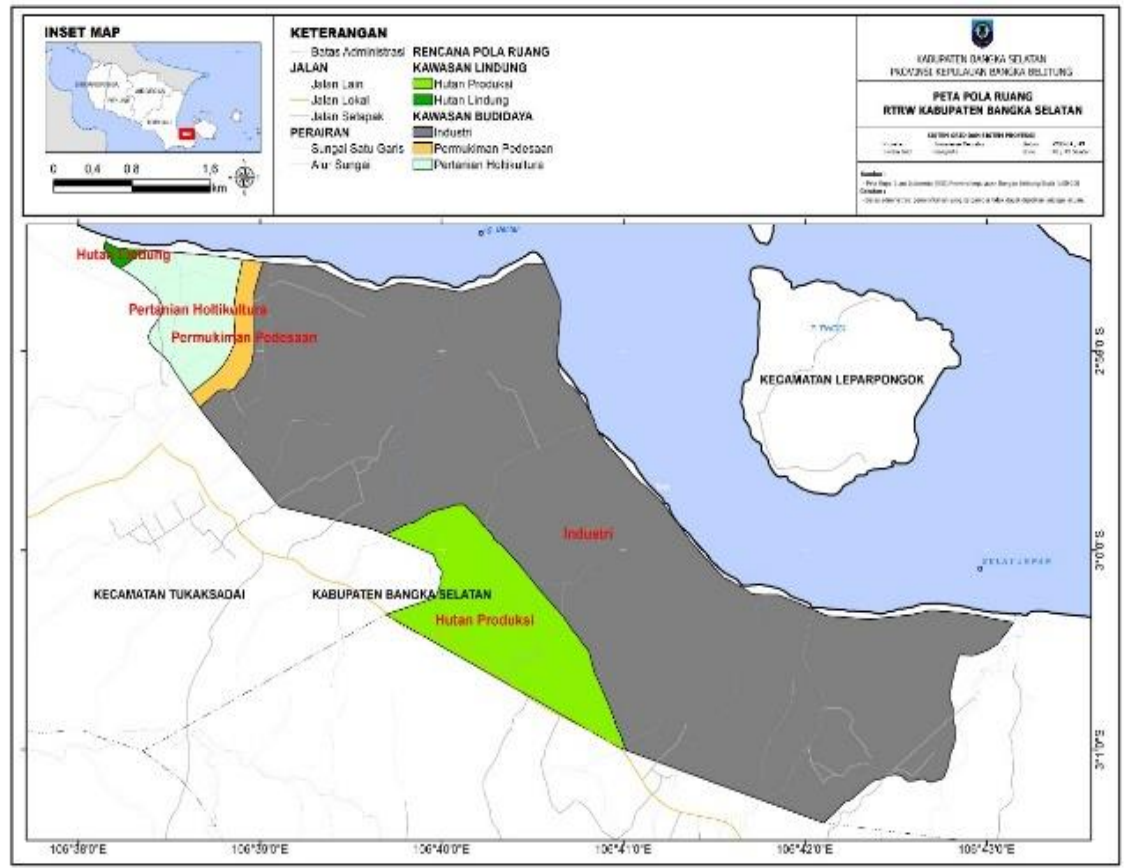

Gambar 3. Peta Pola Ruang (RTRW Bangka Selatan 2014-2034)

Hasil analisis mengenai kesesuaian penggunaan lahan dijelaskan pada tabel 1. Untuk mempermudah melihat kesesuaian kondisi eksisting dan rencana pola ruang dibagi tiga (3) kategori, yaitu Sesuai, Kurang Sesuai dan Penyimpangan

Tabel 1. Analisis Kesesuaian Penggunaan Lahan

\begin{tabular}{|c|c|c|c|}
\hline Rencana Pola Ruang & Kondisi Eksisting & $\begin{array}{l}\text { Luas } \\
\text { (Ha) }\end{array}$ & Kesesuaian* \\
\hline Hutan Lindung & Hutan Mangrove Sekunder & 4,77 & Sesuai \\
\hline Hutan Produksi & Belukar Rawa & 63,96 & Kurang Sesuai \\
\hline Hutan Produksi & Pemukiman & 9,36 & Penyimpangan \\
\hline Hutan Produksi & Pertambangan & 1,53 & Sesuai \\
\hline Hutan Produksi & Pertanian Lahan Kering Bercampur Semak & 138,77 & Sesuai \\
\hline Industri & Belukar Rawa & 823,67 & Kurang Sesuai \\
\hline Industri & Hutan Mangrove Sekunder & 31,18 & Kurang Sesuai \\
\hline Industri & Pemukiman & 13,90 & Penyimpangan \\
\hline Industri & Pertambangan & 141,28 & Sesuai \\
\hline Industri & Pertanian Lahan Kering Bercampur Semak & 273,55 & Penyimpangan \\
\hline Industri & Rawa & 176,72 & Kurang Sesuai \\
\hline Industri & Tanah Terbuka & 98,19 & Kurang Sesuai \\
\hline Permukiman Pedesaan & Hutan Mangrove Sekunder & 2,96 & Kurang Sesuai \\
\hline Permukiman Pedesaan & Pemukiman & 9,18 & Sesuai \\
\hline Permukiman Pedesaan & Pertanian Lahan Kering Bercampur Semak & 17,88 & Penyimpangan \\
\hline Pertanian Holtikultura & Hutan Mangrove Sekunder & 20,19 & Kurang Sesuai \\
\hline Pertanian Holtikultura & Pemukiman & 0,03 & Penyimpangan \\
\hline Pertanian Holtikultura & Pertanian Lahan Kering Bercampur Semak & 77,21 & Sesuai \\
\hline
\end{tabular}

* Keterangan Kesesuaian;Sesuai= kondisi perencanaan telah sesuai dengan kondisi eksisting. Kurang Sesuai= kondisi perencanaan belum/tidak seperti kondisi eksisting, tidak terlalu sulit untuk mewujudkan perencanaan. Penyimpangan = kondisi perencanan tidak sesuai dengan kondisi eksisting 


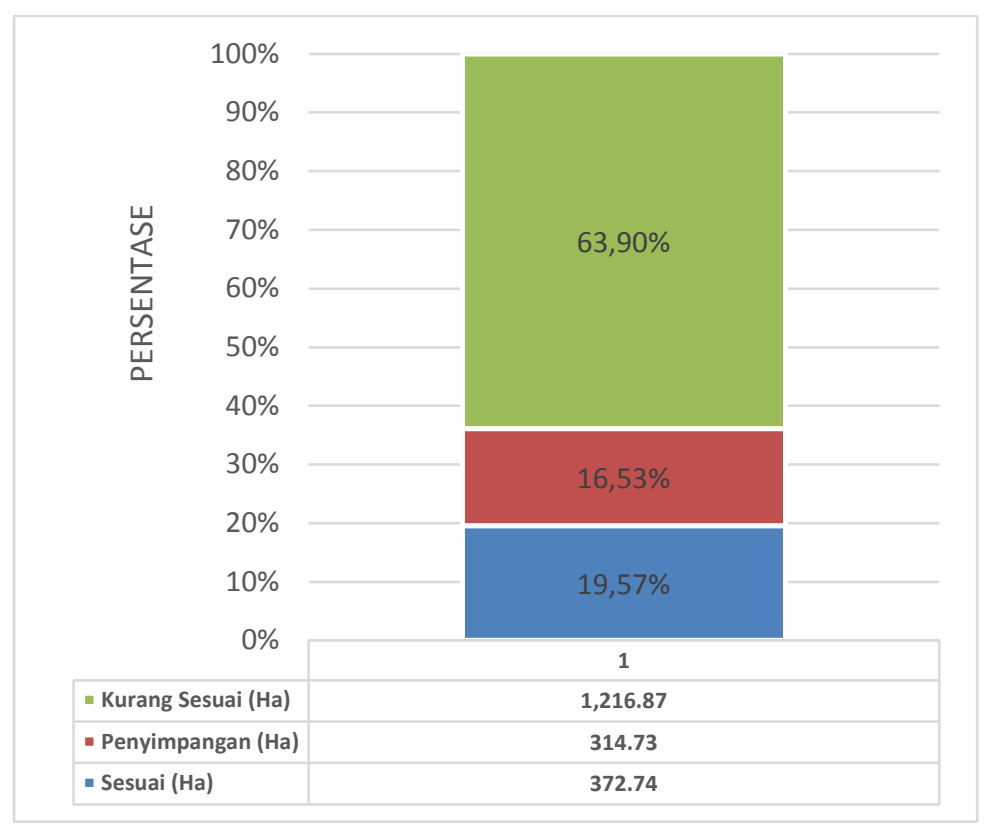

Gambar 4. Kesesuaian Penggunaan Lahan

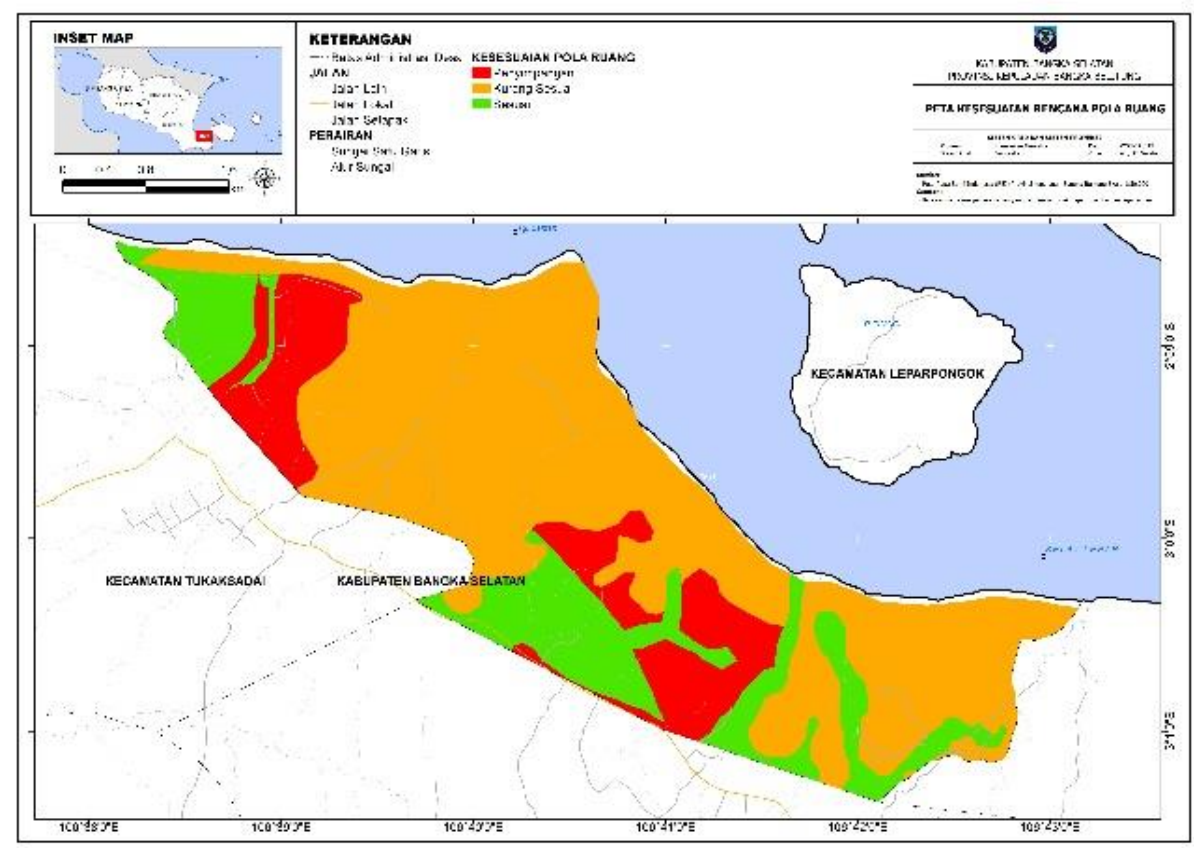

Gambar 5. Peta Kesesuaian Pola Ruang

Kondisi eksisting (penutupan lahan) dibandingkan dengan pola ruang yang terdapat pada Dokumen RTRW, terlihat di Gambar 4 dan Gambar 5 menunjukkan ada tiga kategori kesesuaian. Kategori Sesuai terdapat 19,57\% dari total luas desa Tukak, atau seluas 372,74 Ha. Lokasi berada di daerah selatan daerah Tukak (warna hijau pada Gambar 5). Kategori kurang sesuai ditampilkan di (warna jingga pada Gambar 5) daerah tengah desa Tukak. Sedangkan penyimpangan terjadi pada beberapa daerah di desa Tukak 314,73 Ha atau seluas 16,53\% dari total luasan desa Tukak.

Adapun kondisi eksisting yang belum sesuai dengan rencana pola ruang dikatakan tidak/belum sesuai dengan rencana pola ruang karena kawasan tersebut direncanakan untuk dijadikan hutan produksi, sedangkan kondisi penggunaan lahan eksisting adalah berupa pemukiman. Untuk mengatasi hal ini, pemerintah yang berwenang harus dengan tegas memberikan sosialisasi terhadap masyarakat yang berada pada pemukiman ini bahwa kawasan pemukiman mereka adalah hutan produksi yang seharusnya tidak boleh dibangunkan kawasan pemukiman. Perizinan terkait penggunaan lahan juga harus diperjelas sehingga kedua belah pihak yang terkait tidak mengalami kerugian.

Perubahan penggunaan lahan terhadap kesesuaian tata ruang di Desa Tukak terjadi secara bertahap. Hal ini didasari pada perkembangan zaman seiring dengan kemajuan teknologi dan pertumbuhan penduduk yang semakin meningkat. Beberapa kondisi penggunaan lahan eksisting yang tidak sesuai dengan rencana pola ruang adalah lahan terbuka (kebun) yang telah direncanakan sebagai kawasan industri. Pola ruang ini belum terlaksana sehingga penggunaan lahan eksisting masih dapat berubah atau pola ruang yang direncanakan harus berpedoman kepada tujuan 
pembangunan berkelanjutan untuk mendukung kehidupan yang baik bagi masyarakatnya. Hal ini menjadi dilema tersendiri bagi pemerintah maupun masyarakat setempat. Berkurangnya lahan terbuka atau lahan subur untuk usaha pertanian serta meningkat. Kasusnya kebutuhan pangan lokal terutama beras akibat pertambahan jumlah penduduk menyebabkan pilihan pemenuhan kebutuhan pangan dapat diarahkan pada pemanfaatan lahan terbuka ini. Pemanfaatan lahan terbuka untuk areal pertanian semestinya dapat dilakukan secara efisien dan merupakan alternatif yang sangat tepat khususnya untuk produksi pertanian tanaman pangan. Namun, ketika telah direncanakan untuk dijadikan sebagai kawasan strategis berupa kawasan industri, masyarakat dan pemerintah harus berpikir kritis. Rencana perubahan penggunaan lahan ini bertujuan untuk meningkatkan perekonomian masyarakat Desa Tukak, namun hal ini harus dilakukan analisis terlebih dahulu ke atasnya.

Pada kasus yang terjadi di Desa Tukak, hal ini harus menjadi isu prioritas dalam melakukan pengembangan kawasan industri sehingga dapat meminimalisir kemungkinan-kemungkinan terburuk yang dapat terjadi. Peralihan masyarakat pertanian menjadi masyarakat industri juga menjadi salah satu indikator penting dalam menentukan pola ruang kawasan sehingga dapat mendukung tata ruang wilayah dan penggunaan lahan untuk pembangunan segala fasilitas umum untuk masyarakat.

\section{KESIMPULAN}

Kesimpulan yang dapat diambil dari penelitian ini adalah sebagai berikut :

1. Implementasi Rencana Pola Ruang RTRW Bangka Selatan di tingkat desa (Tukak) hanya 19,57\% yang sesuai.

2. RTRW Bangka Selatan disusun hingga tahun 2034, sehingga masih terdapat waktu untuk memperbesar presentase kesesuaian perencanaan pembangunan.

\section{UCAPAN TERIMAKASIH}

Ucapan terima kasih disampaikan kepada Badan Perencanaan Pembangunan, Penelitian dan Pengembangan Daerah Pemerintah Daerah Kabupaten Bangka Selatan dan Pusat Kajian Sumberdaya Perairan dan Pulau Kecil (PKSP2K) Lembaga Penelitian dan Pengabdian Masyarakat Universitas Bangka Belitung, terkait dengan bantuan pendanaan dan perijinan melaksanakan penelitian

\section{DAFTAR PUSTAKA}

Subagyo, A., 2017. Sinkronisasi RTRW Pembangunan Propinsi Jawa Barat dan RTRW Pertahanan Darat Kodam III/Siliwangi. Jurnal Agregasi, 4(2).

Wirosoedarmo, R., Widiatmono, J.B.R. and Widyoseno, Y., 2014. Rencana Tata Ruang Wilayah (RTRW) Berdasarkan Daya Dukung Lingkungan Berbasis Kemampuan Lahan. Agritech, 34(4), pp.463-472.

Badan Informasi dan Geospasial (BIG), 2018. Moderasi Peta Tata Ruang Dalam Perspektif Penyusunan Tata Ruang Wilayah. Disampaikan dalam pelatihan asistensi dan supervisi pemetaan tata ruang untuk PPIDS. Bogor, 30 juli 2018

Rully, P., 2016. Analisis Konsistensi RTRW Dengan Penggunaan Lahan Serta Pemetaan Resiko Bencana Longsor Di Kota Padang (Doctoral dissertation, Universitas Andalas).

Hidayati, I.N. and Toyibullah, Y., 2011. Kajian Indeks Potensi Lahan Terhadap Pemanfaatan Rencana Tata Ruang Wilayah Menggunakan Sistem Informasi Geografis Di Kabupaten Sragen. MAJALAH ILMIAH GLOBE, 13(2).

Anoraga, S., 2018. Harmonisasi Perda Nomor 4 Tahun 2011 Tentang RTRW Kota Malang Dengan PerundangUndangan Bidang Lingkungan Hidup. Jurnal Ilmiah Hukum LEGALITY, 25(2), pp.232-246.

Napitupulu, M.Y., Hakim, A. and Noor, I., 2016. Penerapan Prinsip Good Governance Dan Pengaruhnya Terhadap Penyusunan Rencana Tata Ruang Wilayah (RTRW) Dalam Perencanaan Tata Ruang Daerah Studi pada Penyusunan RTRW Kabupaten Serdang Bedagai. WACANA, Jurnal Sosial dan Humaniora, 19(4).

Wirasaputri, N.M., 2014. Proses Penyusunan Rencana Tata Ruang dalam Kaitan Kelestarian Fungsi Lingkungan Hidup. Kanun: Jurnal Ilmu Hukum, 16(1), pp.129-146.

Batudoka, Z. 2005. Evaluasi Pemanfaatan Ruang dan Struktur Tata Ruang Wilayah Kabupaten Tolitoli. SMARTek, $3(4)$. 
